\title{
Laser Induced Raman Spectra of Some Tungstates and Molybdates*
}

\author{
R. K. Khanna, ** W. S. Brower, B. R. Guscott, $* *$ and E. R. Lippincott** \\ Institute for Materials Research, National Bureau of Standards, Washington, D.C. 20234
}

(August 3, 1967)

The Raman spectra of single crystals of $\mathrm{CaWO}_{4}$. $\mathrm{CaMoO}_{4}, \mathrm{PbWO}_{4}$. and $\mathrm{PbMoO}_{4}$ have been recorded using a He-Ne laser $(\lambda=6328 \mathrm{~A})$ and an Argon ion laser $(\lambda=4880 \mathrm{~A})$ as the exciting radiation sources. The polarization data have enabled us to classify unambiguously the observed fundamentals into the Raman active species of the point group $\mathrm{C}_{\mathrm{th}}$ to which these crystals belong. The comparison of the spectra of these crystals in the low frequency region has also enabled us to make a rough classification of the bands into the rotational and the translational lattice vibrations.

Key Words: Molybdates, Raman spectra, tungstates.

\section{Introduction}

The tungstates and molybdates of the alkaline earths present rather simple cases for correlation of their Raman spectra with the crystal structure. With the availability of high-powered monochromatic laser radiation the Raman spectra of properly oriented single crystals can enable an unambiguous classification of the vibrational modes into the respective species of the point group to which these crystals belong.

The Raman spectrum of $\mathrm{CaWO}_{4}$ has been reported by Russell and Louden [1]. ${ }^{1}$ The authors have been able to identify 11 of the 13 expected long wavelength fundamentals. A comparison with the spectra of $\mathrm{PbWO}_{4}$ as well as the molybdates of calcium and lead was considered desirable in an effort to get detailed information on the nature of the vibrational modes and to attempt to identify the two missing vibrations of $\mathrm{CaWO}_{4}$. The results of the analysis of these spectra form the basis of this report.

\section{Experimental Procedure}

The tungstate and molybdate crystals were grown by the Czochralski method. They were then oriented by means of the Laue back reflection $x$-ray method,

*The work carried out at the University of Maryland has been supported in part by the Advanced Research Projects Agency and a grant from the U.S. Army Research Office. Durham. N.C. For the crystal growth work at the National Bureau of Standards the author wratefully acknowledge support from the U.S. Atomic Energy Commission.

**Address: Department of Chemistry, University of Maryland, College Park. Md. 20740.

' Figures in brackets indicate the literature references at the end of this paper.

Essentially similar results and much stronger Raman bands were obtained with the argon ion laser $(\lambda=4880 \mathrm{~A})$ subsequently cut and polished to the shape of cubes with the edges coinciding with the major crystallographic axes.

The Raman spectra were recorded on a Cary 81 spectrophotometer equipped with a Helium-Neon Laser $(\lambda=6328 \mathrm{~A})^{2}$ with the incident light perpendicular to the (010) and (001) faces (i.e., along $b$ and $c$ directions). One of the crystallographic axes was made to coincide with the direction of polarization of the incident beam and the scattered light with the components $\|$ and $\perp$ to the direction of the incident polarization was recorded.

Since the $x$ and $y$ crystallographic directions are equivalent (as will be elaborated upon in the next section) some of the orientations gave identical spectra. The four independent traces for $\mathrm{PbWO}_{4}$ are reproduced in figure 1 (a-d). The corresponding traces for $\mathrm{PbMoO}_{4}$ are produced in figure 2 (a-d).

\section{Discussion}

The tungstates and molybdates of calcium and lead belong to the well-known scheelite structure (space group $\left.{ }^{1} 4_{1 / a}-C_{4 h}^{6}\right)[2,3,4]$. The cell of the body-centered tetragonal lattice contains 4 molecules. Since the molecules at the body center are related to those at the corners by simple translations the number of independent vibrational modes of the lattice correspond to those of only two molecules. The usual group theoretical analysis [5] gives the distribution of the vibrations into the irreducible representations of the point group $\mathrm{C}_{4 \mathrm{~h}}$ as follows

$$
\Gamma=3 \mathrm{~A}_{g}+5 \mathrm{~B}_{g}+5 \mathrm{E}_{g}+4 A_{u}+3 B_{u}+4 E_{u} .
$$


The species with the subscript $g$ are infrared inactive and those with the subscript $u$ are Raman inactive. The 13 Raman active vibrations may be classified into two categories, namely, the internal modes of the $\mathrm{XO}_{4}=(\mathrm{X}=\mathrm{W}$ or Mo $)$ units and the lattice modes involving the motion of the rigid units. Even though such a classification is convenient, it should be borne in mind that some of the internal modes (particularly the bending modes) may be in strong interaction with some of the lattice modes.

The tetrahedral $\mathrm{XO}_{4}^{-}$units occupy $\mathrm{S}_{4}$ sites in the lattice. The correlation diagram below [5] gives the site as well as the factor group splitting of the internal modes. The last column in the table gives the proper combinations of the polarizability components for the Raman active species for the group $\mathrm{C}_{4 \mathrm{~h}}$.

Figures la and $\mathrm{b}$ give the Raman spectra of $\mathrm{PbWO}_{4}$ with the incident radiation along the $y$-direction with the electric vector $\|$ to the $z$ axis and the scattered light collected with the vibration directions of the analyser $\|$ and $\perp$ to the $z$ axis respectively. These two traces show, therefore, the vibrations for which $\alpha_{z z}$ and $\alpha_{x y}$ (respectively) are nonzero. Similarly, the spectra reproduced in figure $l c$ and $d$, shows the vibrations for which $\alpha_{x x}$ (or $\alpha_{y y}$ ) and $\alpha_{x y}$ (respectively) are nonzero. With these basic theoretical results in mind, the interpretation of the spectra becomes fairly straight-forward.

TABLE 1. Site and factor group splittings of the vibrational modes of the $\mathrm{XO}_{4}$ ions in the scheelite structure

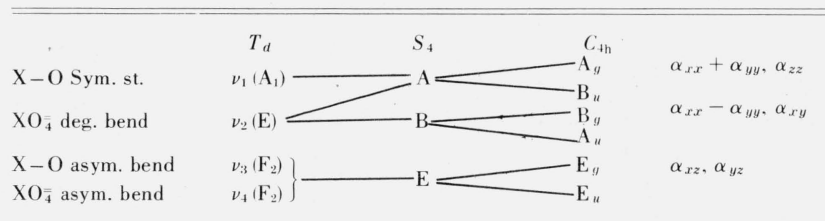

Thus, the band at $\sim 900 \mathrm{~cm}^{-1}$ for which $\alpha_{z z}, \alpha_{x x}$ and $\alpha_{y y}$ are nonzero is associated with the $\nu_{1}\left(\mathbf{A}_{y}\right)$ mode. The bands at $\sim 764 \mathrm{~cm}^{-1}$ and at $\sim 748 \mathrm{~cm}^{-1}$ which have the characteristics $\mathrm{B}_{g}$ and $\mathrm{E}_{y}$ respectively, appear to be the 2 split components of the $\nu_{3}\left(\mathrm{~F}_{2}\right)$ mode of the $\mathrm{XO}_{\overline{4}}$ ion. The corresponding bending mode $\nu_{4}\left(\mathrm{~F}_{2}\right)$ also shows 2 components $\left[353 \mathrm{~cm}^{-1}\left(\mathrm{E}_{g}\right)\right.$ and $348 \mathrm{~cm}^{-1}$ $\left(\mathrm{B}_{g}\right) \mid$. A relatively smaller splitting of $\nu_{4}\left(\mathrm{~F}_{2}\right)$ compared to that of $\nu_{3}\left(\mathrm{~F}_{2}\right)$ is quite general for the tetrahedral ions and has received an explanation by Greenwood [6]. In this connection mention may be made of the observation of only one component of $\nu_{4}$ in the spectrum of $\mathrm{CaWO}_{4}$ reported by Russell and Louden. Our traces for $\mathrm{CaWO}_{4}$ show two components for $\nu_{4}[403$ $\mathrm{cm}^{-1}\left(\mathrm{~B}_{g}\right)$ and $397 \mathrm{~cm}^{-1}\left(\mathrm{E}_{g}\right) \mid$. The doubly degenerate mode $\nu_{2}(\mathrm{E})$ should also be split in the lattice. The band is rather broad and appears with components $\alpha_{z z}$, $\alpha_{x x}, \alpha_{y y}$, and $\alpha_{x y}$. Apparently, the small splitting, if any, is lost in the band width. The internal modes of $\mathrm{PbMoO}_{4}, \mathrm{CaWO}_{4}$ and $\mathrm{CaMoO}_{4}$ also show very similar results. The assignments of the observed bands in all the spectra are given in table 2 .
TABLE 2. Assignments of the fundamental vibrational modes of $\mathrm{AXO}_{4} \mathrm{~A}=\mathrm{Ca}, \mathrm{Pb}: \mathrm{X}=\mathrm{W}$. Mo

(Designated by wave numbers in $\mathrm{cm}^{-1}$ )

\begin{tabular}{|c|c|c|c|c|c|}
\hline & $\mathrm{CaWO}_{4}$ & $\mathrm{PbWO}_{4}$ & $\mathrm{CaMoO}_{4}$ & $\mathrm{PbMoO}_{4}$ & \\
\hline \multicolumn{6}{|l|}{$\begin{array}{r}\text { Russell \& } \\
\text { Louden }\end{array}$} \\
\hline $86\left(\mathrm{~B}_{\imath}\right)$ & $\begin{array}{l}86\left(\mathrm{~B}_{q}\right) \\
86\left(\mathrm{E}_{y}\right) \\
? \\
16\left(\mathrm{E}_{u}\right)\end{array}$ & $\begin{array}{l}76\left(\mathrm{~B}_{g}\right) \\
61\left(\mathrm{E}_{g}\right) \\
52\left(\mathrm{~B}_{g}\right) \\
86\left(\mathrm{E}_{w}\right)\end{array}$ & $\begin{aligned} & 111\left(\mathrm{~B}_{g}\right) \\
& 111\left(\mathrm{E}_{g}\right) \\
& ? \\
& 140\end{aligned}$ & $\begin{array}{r}75\left(\mathrm{~B}_{q}\right) \\
61\left(\mathrm{E}_{q}\right) \\
64\left(\mathrm{~B}_{g}\right) \\
100\left(\mathrm{E}_{\vartheta}\right)\end{array}$ & 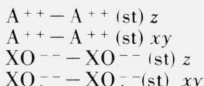 \\
\hline $\begin{array}{l}118\left(\mathbf{E}_{y}\right) \\
180 ?\end{array}$ & $116\left(\mathrm{E}_{\imath)}\right)$ & $86\left(\mathrm{E}_{q}\right)$ & $140\left(\mathrm{E}_{g}\right)$ & $100\left(\mathrm{E}_{y g}\right)$ & $\mathrm{XO}_{4}^{--}-\mathrm{XO}_{4}^{-}$(st) $x y$ \\
\hline $\begin{array}{l}196\left(\mathbf{E}_{q}\right) \\
210\left(\mathrm{~A}_{q}\right) \\
281\left(\mathrm{E}_{q}\right)\end{array}$ & $\begin{array}{l}196\left(\mathrm{E}_{q}\right) \\
210\left(\mathrm{~A}_{y}\right)\end{array}$ & $\begin{array}{l}187\left(\mathrm{E}_{g}\right) \\
178\left(\mathrm{~A}_{g}\right)\end{array}$ & $\begin{array}{l}189\left(\mathrm{E}_{y \jmath}\right) \\
204\left(\mathrm{~A}_{g}\right)\end{array}$ & $\begin{array}{l}190\left(\mathrm{E}_{y}\right) \\
164\left(\mathrm{~A}_{y}\right)\end{array}$ & $\begin{array}{l}\mathrm{R}_{x y} \\
\mathrm{R}_{z}\end{array}$ \\
\hline $334\left(\mathrm{~A}_{y}\right)$ & $\begin{array}{l}333\left(\mathrm{~A}_{q}\right) \\
333\left(\mathrm{~B}_{q}\right)\end{array}$ & $\begin{array}{l}322\left(\mathrm{~A}_{y}\right) \\
322\left(\mathrm{~B}_{y}\right)\end{array}$ & $\begin{array}{l}322\left(\mathbf{A}_{g}\right) \\
322\left(\mathbf{B}_{g}\right)\end{array}$ & $\begin{array}{l}314\left(\mathrm{~A}_{y}\right) \\
317\left(\mathrm{~B}_{y}\right)\end{array}$ & $\nu_{2}$ \\
\hline $403\left(\mathrm{~B}_{y}\right)$ & $\begin{array}{l}397\left(\mathrm{~B}_{q}\right) \\
403\left(\mathrm{E}_{q}\right)\end{array}$ & $\begin{array}{l}348\left(\mathrm{~B}_{\eta t}\right) \\
353\left(\mathrm{E}_{t}\right)\end{array}$ & $\begin{array}{l}390\left(\mathrm{~B}_{q}\right) \\
404\left(\mathrm{E}_{q}\right)\end{array}$ & $\begin{array}{l}348\left(\mathrm{~B}_{g}\right) \\
356\left(\mathrm{E}_{u}\right)\end{array}$ & $\nu_{4}$ \\
\hline $794\left(\mathbf{E}_{\ell}\right)$ & $795\left(\mathrm{E}_{g}\right)$ & $748\left(\mathrm{E}_{q}\right)$ & $794\left(\mathrm{E}_{q}\right)$ & $744\left(\mathrm{E}_{q}\right)$ & \\
\hline $838\left(\mathrm{~B}_{u}\right)$ & $838\left(\mathrm{~B}_{g}\right)$ & $764\left(\mathrm{~B}_{y}\right)$ & $844\left(\mathrm{~B}_{g}\right)$ & $764\left(\mathrm{~B}_{y}\right)$ & $\nu_{3}$ \\
\hline $922\left(\mathrm{~A}_{y}\right)$ & $911\left(\mathrm{~A}_{y}\right)$ & $900\left(\mathrm{~A}_{4 \prime}\right)$ & $878\left(\mathrm{~A}_{f /}\right)$ & $868\left(\mathrm{~A}_{t \prime}\right)$ & $\nu_{1}$ \\
\hline
\end{tabular}

The bands below $300 \mathrm{~cm}^{-1}$ are predominantly due to lattice modes and their assignments to the various species follow the same arguments as for the internal modes. $\mathrm{PbWO}_{4}$ and $\mathrm{PbMoO}_{4}$ show six bands with the predicted polarization characteristics for the fundamentals. $\mathrm{CaWO}_{4}$ and $\mathrm{CaMoO}_{4}$ show fewer bands. A comparison of the spectra of the four crystals and a rough description of the lattice modes might enable us to locate the missing modes in the latter two crystals. The lattice modes belong to the following irreducible representations of the group $\mathrm{C}_{4 \mathrm{~h}}$.

$$
\Gamma=\mathrm{A}_{g}+2 \mathrm{~B}_{g}+3 \mathrm{E}_{g} .
$$

The mode $A_{g}$ involves torsional motion $\left(R_{2}\right)$ of the $\mathrm{XO}_{\overline{4}}$ about the $z$ axis and the torsional motion about the two orthogonal axes $\left(\mathbf{R}_{x}\right.$ and $\left.\mathbf{R}_{y}\right)$ in the $x-y$ plane have the $\mathrm{E}_{g}$ characteristics.

The assignment $\mathrm{R}_{z}\left(\sim 178 \mathrm{~cm}^{-1}\right.$ in $\mathrm{PbWO}_{4}$ and $164 \mathrm{~cm}^{-1}$ in $\mathrm{PbMoO}_{4}$ ) is quite unambiguous as this is the only band possessing nonzero $\alpha_{x x}, \alpha_{y y}$, and $\alpha_{z z}$ components. For the most favorable arrangement in a cubic lattice $\mathbf{R}_{x}, \mathbf{R}_{y}$, and $\mathbf{R}_{z}$ would coincide. Consequently, the band adjacent to $R_{z}\left(\sim 187 \mathrm{~cm}^{-1}\right)$ having nonzero $\alpha_{x z}$ and $\alpha_{y z}$ components is assigned to $\mathrm{R}_{x}$ and $\mathrm{R}_{y}\left(\mathrm{E}_{g}\right)$. The bands at $61 \mathrm{~cm}^{-1}\left(\mathrm{E}_{g}\right)$ and $76 \mathrm{~cm}^{-1}$ $\left(\mathrm{B}_{4}\right)$ in the spectrum of $\mathrm{PbWO}_{4}$ have almost exact counterparts in that of $\mathrm{PbMoO}_{4}$ and, therefore, are assigned to $\mathrm{Pb}-\mathrm{Pb}$ stretches in the $x-y$ plane $\left(\mathrm{E}_{y}\right)$ and along the $z$ axis $\left(\mathrm{B}_{g}\right)$ respectively. The remaining two bands, namely $52 \mathrm{~cm}^{-1}\left(\mathrm{~B}_{g}\right)$ and $86 \mathrm{~cm}^{-1}\left(\mathrm{E}_{g}\right)$ in the spectrum of $\mathrm{PbWO}_{4}\left[64 \mathrm{~cm}^{-1}\left(\mathrm{~B}_{g}\right)\right.$ and $86 \mathrm{~cm}^{-1}\left(\mathrm{E}_{g}\right)$ in $\mathrm{PbMoO}_{4} \mid$ may be assigned to the translatory lattice modes involving motions of the $\mathrm{XO}_{\overline{4}}$ units.

Only four of the six lattice modes of $\mathrm{CaWO}_{4}$ and $\mathrm{CaMoO}_{4}$ can be assigned with certainty (table 2). However, an examination of the spectra reveals that the band at $\sim 86 \mathrm{~cm}^{-1}$ in $\mathrm{CaWO}_{4}\left(\sim 110 \mathrm{~cm}^{-1}\right.$ in $\mathrm{CaMoO}_{4}$ ) have both $\mathrm{B}_{g}$ and $\mathrm{E}_{g}$ polarizations. It is quite likely that the modes involving translations of $\mathrm{Ca}^{++}$ along the $z$ axis and in the $x-y$ plane still retain their degeneracy. The other missing mode (presumably involving translation of the $\mathrm{XO}_{\overline{4}}$ units along the $z$ direction) is presumably too weak. Russell and Louden 
have reported two weak bands, one at $\sim 180 \mathrm{~cm}^{-1}$ with unspecified polarization and the other at $\sim 281$ $\mathrm{cm}^{-1}\left(\mathrm{E}_{q}\right)$ in the spectrum of $\mathrm{CaWO}_{4}$. Our records also show these two bands, but the former appears in all orientations and the latter is rather broad, and may be due to the second order processes.

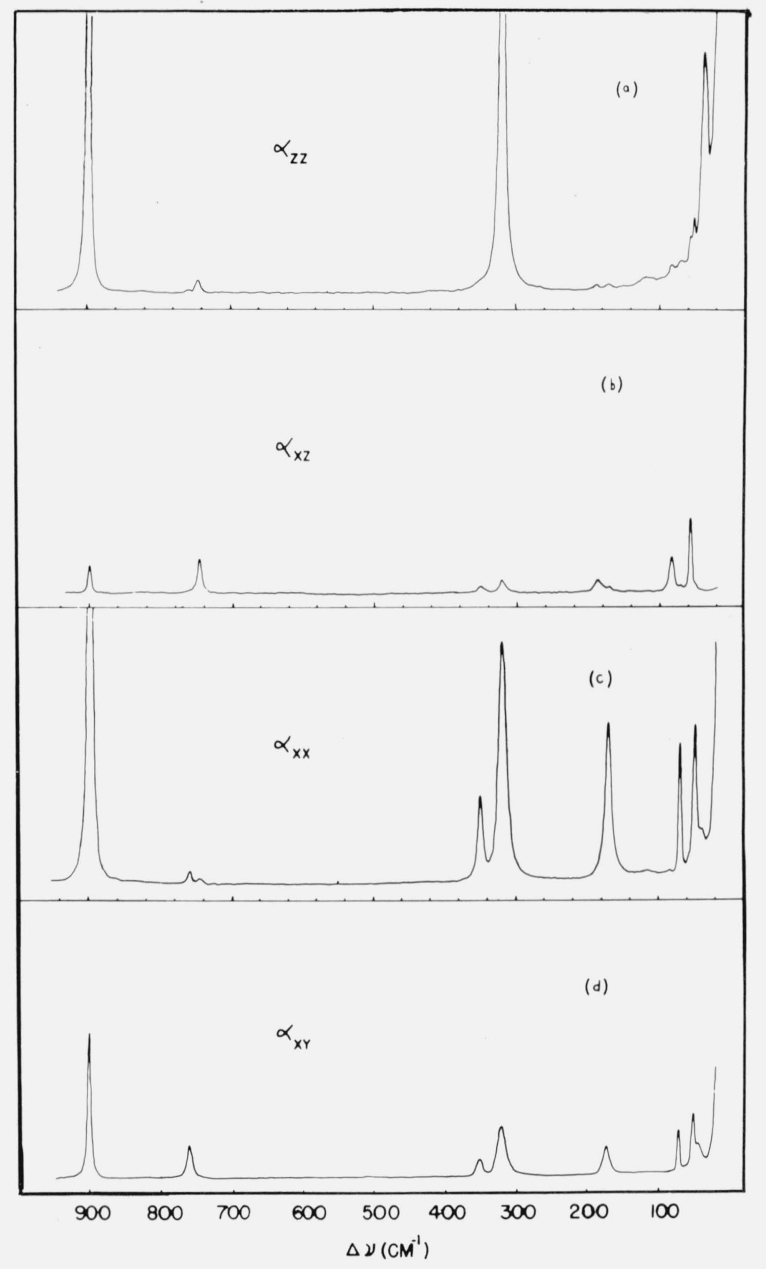

FigURE 1. Raman spectrum of $\mathrm{PbWO}_{4}$, spectral slit width $\sim 3 \mathrm{~cm}^{-1}$. (a) $\alpha_{z z}$ component showing $\mathbf{A}_{g}$ vibrations

(b) $\alpha_{x y}\left(=\alpha_{y z}\right)$ component showing $\mathbf{E}_{y /}$ vibrations

(c) $\alpha_{r r}$ component showing $\mathrm{A}_{y}$ and $\mathrm{B}_{y}$ vibrations

(d) $\alpha_{x y}$ component showing $\mathbf{B}_{y}$ vibrations.

Weak residual components of $\mathrm{A}_{l}$ and $\mathrm{B}_{y}$ in (b) are due to convergence of the scattered beam.

Finally, a remark on the traces in figure $1 \mathrm{~d}$ and figure $2 \mathrm{~d}$ is called for. It is seen that the band at $\sim 900 \mathrm{~cm}^{-1}\left[\nu_{1}\left(A_{1 g}\right)\right]$ appears with an appreciable intensity with $\alpha_{x y}$ polarization in apparent contradiction with the selection rules. A similar anomaly in the $\nu_{1}\left(\mathrm{~A}_{1 q}\right)$ band of calcite $\left(\sim 1086 \mathrm{~cm}^{-1}\right)$ has been noted in the past and its explanation in terms of unspecified convergence error has been attempted. ${ }^{3}$

See reference 7 and the cross references indicated there
By a detailed analysis of the Raman scattering in calcite, Porto et al. [7], have concluded that the polarization errors can be quite large if the incident (convergent) or the scattered light travels along the optic axis of a uniaxial crystal. For a ray diverging as little as $1^{\circ}$ from the optic axis the depolarization is

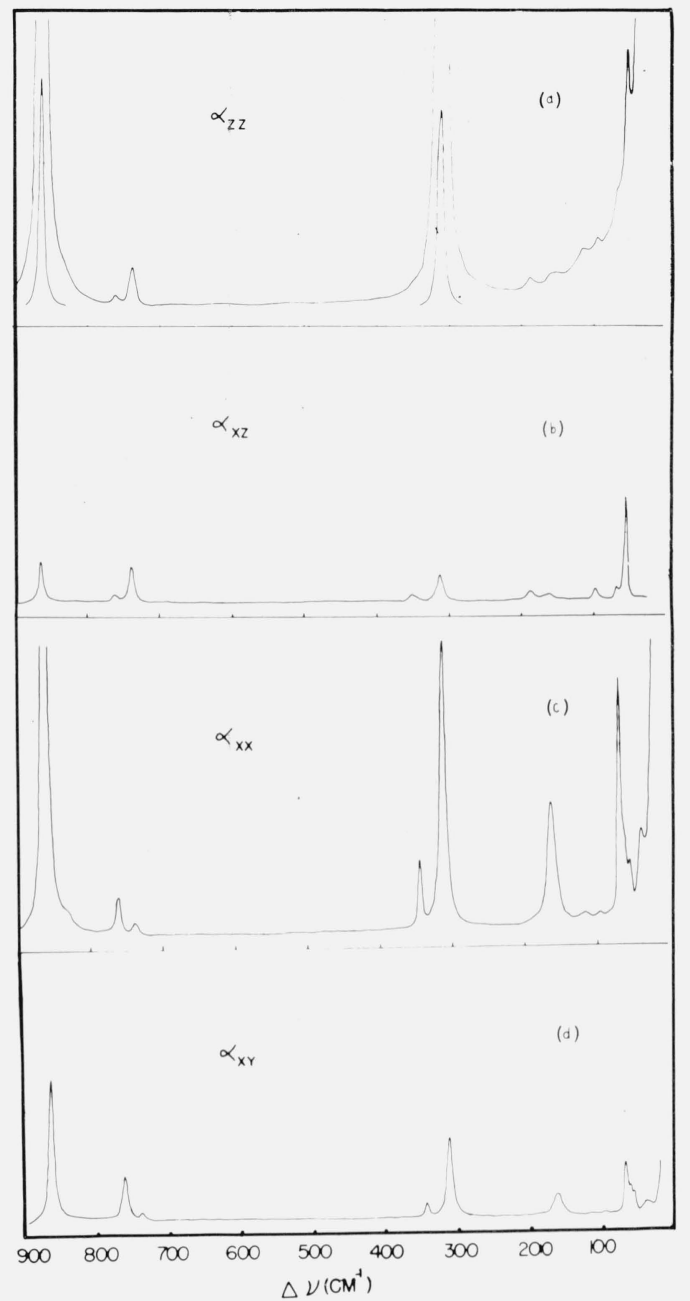

Figure 2. Raman spectrum of $\mathrm{PbMoO}_{4}$. Captions in the figure have the same meaning as in figure 1.

more or less complete after the beam traverses a path length of $\sim 5 \mathrm{~mm}$. The spectra reported in figure ld and figure $2 \mathrm{~d}$ were recorded with the incident light along the $z$ axis (optic axis) from a focused laser beam with $x$ polarization and the scattered light with the $y$ component was collected within a cone of an estimated $6^{\circ}$ half angle, thereby giving a finite intensity to the $\mathrm{A}_{g}$ bands.

The authors are indebted to E. N. Farabaugh for the $\mathrm{x}$-ray orientation of the crystals used in this study and to H. S. Peiser for encouragement and helpful discussions. 


\section{References}

[1] J. P. Russell and R. Louden, Proc. Phys. Soc. London 85, 1029 (1965).

[2] R. D. Burbank, Acta Cryst. 18, 88 (1965).

[3] A. Zalkin and T. H. Templeton, J. Chem. Phys. 40, 501 (1964).

$[4]$ B. C. Frazer and I. Almodoran, J. Chem. Phys. 40, 504 (1964).
[5] E. B. Wilson, J. C. Decius and P. C. Cross, Molecular Vibrations (McGraw-Hill Book Co., New York, N.Y., 1955).

[6] N. N. Greenwood, J. Chem. Soc., 3811 (1959).

[7] S. P. S. Porto, J. A. Giordmaine and T. C. Damen, Phys. Rev. 147, 608 (1966).

(Paper 72A1-483) 